\title{
BIG DATA Y ETNOLOGÍA
}

\section{JOSEPH P. FELDMAN*}

No es en un futuro muy lejano que la indexación automatizada de datos etnográficos es decir, la organización de segmentos de etnografías por temas, llevada a cabo con una mínima supervisión humana- será una realidad tecnológica. Avances en áreas tales como la lingüística computacional han hecho posible pensar en este avance como algo que podría pertenecer a un futuro antropológico no tan distante. Ya no se trata de un auto volador zigzagueando entre rascacielos, sino de algo más parecido a una ajetreada calle de Londres llena de vehículos autónomos.

En este artículo ofrezco algunas reflexiones preliminares de cómo nosotros, como antropólogos socioculturales, podríamos involucrarnos con la posibilidad de la indexación automatizada, y cómo, a su vez, esta tecnología podría servir como una oportunidad para cuestionarnos ciertos supuestos y prácticas arraigadas en nuestra disciplina. Introduzco mis comentarios señalando que, para antropólogos que investigan dentro de la tradición de la investigación transcultural o cross-cultural research (Ember \& Ember, 2009), los beneficios ya son evidentes. Desde sus inicios, la investigación transcultural ha dependido de las múltiples horas de labor humana que se requieren para indexar etnografías; reducir el tiempo y los recursos usados en esta parte del proceso, podría posiblemente llevar a más y mejor investigación de manera bastante directa.
Ahora bien, para la gran mayoría de los antropólogos, la utilidad de tales avances no es tan clara. Una reacción, por supuesto $-y$ que podría ser la de facto para la mayoría- es ignorar la posibilidad de que máquinas procesen textos etnográficos y seguir trabajando como siempre, tal vez desestimando tales técnicas como inherentemente reduccionistas o de cierto modo inapropiadas para los objetivos de la teoría contemporánea. Mi objetivo aquí no es proclamar que tomar tal posición representaría un grave error para la disciplina, sino proponer una posible manera de avanzar, una que podría redirigir nuestra atención a hallazgos y contenidos en el registro etnográfico contemporáneo.

Al igual que en otras disciplinas académicas (y, más generalmente, otros dominios de la vida social), hace tiempo que la antropología experimenta una suerte de exceso de información. Parafraseando las reflexiones de un colega senior. si alguna vez fue posible estar al día con la literatura de la propia región, ahora es a menudo un desafío procesar el diluvio de publicaciones dentro del propio país o cultura de interés. Las tendencias de publicación tales como el aumento de digitalización y el surgimiento de algoritmos amigables con el usuario, parecieran empujarnos hacia la especialización, tal como las páginas de Facebook y los feeds de Twitter nos proveen con contenido consistente con nuestros intereses y creencias políticas. 
Aún así, el motivo de preocupación no es simplemente el hecho de que estemos leyendo de forma más restringida (después de todo, leer más restringidamente no necesariamente es malo). Propongo que nuestros patrones de lectura y citación de trabajos antropológicos, al menos en antropología interpretativa convencional (mainstream), tienden a evidenciar el poco interés real en el registro etnográfico, a pesar de nuestros continuos esfuerzos hacia la existencia de un proyecto comparativo más amplio. La tendencia prevaleciente, especialmente para trabajos fuera de las áreas de interés propias, es guiarse por la teoría, la lectura rápida $y$, cuando es necesario, demostrar conocimiento de los trabajos "correctos" en una revisión bibliográfica. Mientras tanto, una creciente masa de datos etnográficos - tal vez no siempre cargada con los argumentos, sensibilidades teóricas o rasgos estilísticos necesarios para atraer a una audiencia más allá de la regional o especializada en el tema - permanece muy poco utilizada y apreciada.

La ausencia de un marco teórico coherente para organizar hallazgos etnográficos contemporáneos se revela de maneras sutiles pero contundentes. Donde se ha vuelto común burlarse de los teóricos que anuncian grandes proyectos antropológicos solo para luego dejar los detalles y el trabajo empírico a otros, uno podría de igual manera ser aquel etnógrafo que insiste repetidamente en las "contingentes" e "inesperadas" maneras que el Fenómeno $X$ juega en "lugares y momentos históricos específicos", solo para ofrecer una historia que es, en cierto sentido, bastante predecible. Siguiendo una línea similar, se podría argumentar que el creciente interés por la "teoría etnográfica" en años recientes solo ha revelado aún más la poca habilidad y disposición de los antropó- logos para desarrollar nuevas estrategias para la integración de reflexiones etnográficas.

Lo que propongo es una forma de teoría etnográfica un tanto diferente, un enfoque que podría inspirarse en los métodos de la investigación transcultural (cross-cultural research) y aprovechar los avances tecnológicos de nuestro tiempo.

La investigación transcultural es una estrategia que implica analizar textos etnográficos sistemáticamente con el fin de abordar preguntas de investigación. Las preguntas pueden estar relacionadas con la frecuencia de un rasgo cultural -p.e., besarse de manera romántica (Jankowiak et al., 2015) - o pueden implicar poner a prueba relaciones entre temáticas en el registro etnográfico y otras variables (las cuales podrían ser otras temáticas, o cosas tales como el clima, densidad de población, etc.). Las unidades de análisis relevantes son las "sociedades", donde la idea general es tomar muestras dentro de un universo de culturas etnográficamente documentadas y usar análisis de contenido en segmentos relevantes dentro de las etnografías, para monitorear temáticas entre varios casos. Este tipo de investigación ha dependido históricamente del trabajo de instituciones tales como la Human Relations Area Files (HRAF) ${ }^{2}$.

La diferencia entre el planteamiento que esbozo aquí y el de la investigación transcultural es que el enfoque podría centrarse mucho más en la circulación global de ideas e instituciones antes que en la comparación de culturas como tales. Esta reorientación sería consistente con las tendencias generales de la teoría antropológica desde 1980 e, igualmente importante, se 
correspondería con los tipos de textos etnográficos que los antropólogos tienden a producir hoy en día - el estudio orientado a problemas (problem-oriented studies) ha desplazado en gran medida la descripción holística de una cultura. Imagine, por ejemplo, bases de datos etnográficos, como la HRAF, agrupadas por áreas temáticas diferentes: la habilidad de recuperar párrafos relevantes indexados en la mayoría, si no la totalidad, de los trabajos antropológicos existentes en microempresas, programas de Reducción de Emisiones causadas por la Deforestación y la Degradación de los Bosques (REDD, por sus siglas en inglés) o adopción transnacional; la posibilidad, para aquellos interesados, de monitorear sistemáticamente variaciones en cómo las víctimas de guerra perciben las iniciativas nacionales de reconciliación, o ponen a prueba hipótesis sobre las reacciones de pueblos indígenas a industrias extractivas.

Mientras el tipo de enfoque e infraestructura que perfilo podría dejar de lado características centrales de la investigación transcultural (entre ellas, cualquier pretensión de un proyecto etnológico que revise el total de la diversidad cultural registrada para llegar a principios de orden más general), me interesa más lo que podría quedar de este. Este optimismo está basado en la creencia de que la investigación transcultural e instituciones como la HRAF anticiparon algunos de los problemas mencionados arriba.

Primero, al ofrecer una perspectiva coherente para medir la diversidad de textos y casos antropológicos, los métodos de la investigación transcultural responden a la indigestión etnográfica (ethnographic indigestion) de nuestro tiempo. Si bien esta estrategia no está libre de críticas o problemas epistemológicos, uno podría estar presionado a pensar en una mejor manera de producir análisis sistemático y comparativos basados hallazgos etnográficos ${ }^{3}$.

Segundo, los métodos de la investigación transcultural dependen de nociones de autoría y autoridad que están especialmente diseñadas para la era de los "macrodatos" (big data). Bajo el riesgo de sobresimplificar una discusión compleja, la mayoría de los investigadores de la investigación transcultural trabajan desde el supuesto de que hay algo especial en un relato producido por un autor que ha llevado a cabo una investigación prolongada entre un grupo de gente, usa el idioma local y que, idealmente, tiene entrenamiento antropológico o en las ciencias sociales. Hay debates sobre los detalles (p.e., el grado de manejo del idioma, el nivel de experiencia en trabajo de campo), pero si el tema es, por ejemplo, las experiencias de la juventud rural LGBT y nuestra preocupación principal es la fiabilidad de los datos etnográficos para propósitos comparativos, ¿es razonable sugerir que puede haber una pequeña diferencia entre un relato realizado por un profesor de una universidad de la Ivy League y uno realizado por un estudiante de doctorado de una universidad de menor prestigio? ${ }^{4}$

Otra fortaleza relacionada a la HRAF y la investigación transcultural es una tolerancia a la diversidad de enfoques metodológicos que existe entre etnógrafos. Mientras que hallazgos cuantitativos podrían ser considerados más que solo pasajes descriptivos dentro de ciertos esquemas de codificación, el grueso del material con que trabaja la investigación transcultural es cualitativo. Por lo tanto, a diferencia de la mayoría de las propuestas teóricas o metodológicas que se presentan, la 
creación de una infraestructura como la de la HRAF para hacer sentido del registro etnográfico contemporáneo no requeriría ninguna gran revolución y permitiría esencialmente que los antropólogos sociales continúen haciendo lo que hemos estado haciendo como trabajadores de campo y escritores.

Está de más decir que hay un número de problemas sin resolver que he dejado de lado en esta breve discusión. Algunos son de naturaleza más metodológica y organizacional (¿cuáles serían los desafíos específicos asociados a indexar etnografías contemporáneas, orientadas a un problema?, ¿cuán amplias o acotadas serían las áreas temáticas?). Otra serie de preguntas tiene que ver con la aparente ausencia de una necesidad sentida por mayor integración de datos etnográficos en gran parte de la antropología social hoy. ¿Podría ser, por ejemplo, que el tipo de corpus antropológico que describo sería simplemente muy tedioso y gradual (incremental) para el gusto de la mayoría de los antropólogos sociales?

\section{Notas}

\footnotetext{
${ }^{1}$ Este ensayo es una traducción de una editorial que escribí como invitado para la revista Anthropology Today 33(3),1-2 (Feldman, 2017). Agradezco a Martín Aguirre Galilea por su traducción del texto y al cuerpo editorial de Antropologías del Sur (especialmente a Luis Campos) por su interés en mi propuesta de publicar una versión en español.

Si bien la traducción es fiel al texto original, quisiera aprovechar esta oportunidad para plantear dos temas que no considero lo suficiente en mi discusión y que ameritan mayor reflexión: (1) la economía política del acceso a bases de datos como la HRAF, especialmente en países del Sur Global y (2) la sobrerrepresentación histórica de etnografías en inglés (generalmente escritas por autores
}

Para concluir, presento esta idea experimental no tanto porque espere que el programa que describo se convierta en una realidad en un futuro cercano -o que siquiera se convierta en una realidad-. Reconozco que las ideas que discuto pueden parecer exageradas o incluso extravagantes para algunos. Por ahora, un ejercicio útil podría ser parar y considerar algunas de las razones por las que conceptos tales como indexación automatizada, análisis de contenido de textos antropológicos o el "registro de etnografía contemporánea" tiendan a incomodar a los antropólogos sociales. ¿Están nuestras preocupaciones basadas en una visión inherentemente "antropológica" de la investigación académica o reflejarán ciertas herencias disciplinares que merecen ser reconsideradas? En cualquier caso, mi esperanza es que podamos seguir comprometiéndonos con preguntas sobre el exceso de información y la indigestión etnográfica de maneras productivas en los años venideros.

que pertenecen a instituciones norteamericanas o europeas) en dichas bases de datos. Se puede afirmar que estas desigualdades son mucho más urgentes que las diferencias de "estatus" que menciono en el ensayo.

${ }^{2}$ Sobre la historia de la HRAF, véase Lemov (2011).

${ }^{3}$ Para un resumen de críticas humanísticas a la HRAF y la investigación transcultural, véase Tobin (1990, pp. 476-479).

${ }^{4}$ Se podría agregar aquí, "o de una tesis de licenciatura escrita por un/a estudiante de una universidad latinoamericana", dado que estos trabajos frecuentemente presentan análisis que rivalizan (y, a veces, exceden) los de tesis de posgrado norteamericanas y europeas en términos de su profundidad etnográfica. 


\section{Referencias bibliográficas}

Ember, C. \& Ember, M. (2009). Cross-Cultural Research Methods (segunda edición). Lanham, MD: Altamira.

Jankowiak, W., Volsche, S. \& Garcia, J. (2015). Is the RomanticSexual Kiss a Near Human Universal? American Anthropologist 117(3), 535-539.
Lemov, R. (2011). Filing the Total Human: Anthropological Archives from 1928 to 1963. En Camic, C., Gross, N. \& Lamont, M. (eds.), Social Knowledge in the Making (pp. 119-150). Chicago: University of Chicago Press.

Tobin, J. (1990). The HRAF as Radical Text? Cultural Anthropology 5(4),473-487. 